Washington

THE US Congress's Office of Technology Assessment (OTA) has added its voice to those critical of President Reagan's Strategic Defense Initiative (SDI). In a major report published this week (Ballistic Missile Defense Technologies). OTA concludes that SDI offers an opportunity to increase substantially US national security only if the research programme achieves "great technical success" and if the Soviet Union cooperates in a negotiated reduction of strategic nuclear weapons. On the other hand. SDI carries the risk that a vigorous anti-ballistic missile research programme could lead to a race for both offensive and defensive arms, and a further risk that development

\section{Premature death?}

\section{Washington}

THE US Department of Defense (DoD) admitted last week that the scientific satellite destroyed two weeks ago in a successful anti-satellite test was not, as previously described, "obsolete". The satellite was transmitting useful data on the solar corona up until the moment it was destroyed, according to Robert MacQueen of the High Altitude Observatory at the National Center for Atmospheric Research.

The Air Force satellite, which is known as P78-1, was carrying four instruments, according to DoD: a coronograph, called "Solwind", which was still functional at the time of the test; an X-ray monitor, from which data returns were said to be "marginal" due to degraded power supplies; an ultraviolet spectrograph and photometer, which was partly inoperable at the time of the test; and a solar X-ray instrument that had been inoperable for several months. DoD says P78-1 was chosen as a target because it had operational telemetry that allowed an independent test of when the anti-satellite destroyed it. The satellite had already exceeded its designed lifetime and ground support for the satellite was due to have been discontinued in 1987 .

MacQueen is not so dismissive of the value of P78-1. Data from the coronograph, he says, were complementary to those obtained from the National Aeronautics and Space Adminstration's Solar Maximum satellite.

DoD revealed details of $\mathbf{P 7 8 - 1}$ 's functions only after written requests from the Washington Post. A spokesman denied there had been any inconsistency in the satellite's characterization, saying "obsolete" referred only to the suboptimal rate of data production.

Tim Beardsley of a "star wars" type defence without Soviet cooperation could create severe strategic instabilities.

OTA says its report is intended to illuminate, rather than to adjudicate. the debate over star wars. The report critically examines the assumptions that lie behind many of the oft-quoted benefits - and dangers - of SDI. but necessarily stops short of providing firm answers to many of the questions raised.

But OTA notes that although President Reagan's original "star wars" speech of March 1983 referred to a means of rendering nuclear weapons "impotent and obsolete", the administration seems now to accept OTA's assessment that "assured survival of the US population appears impossible to achieve if the Soviets are determined to deny it to us". However. OTA grants that strategic defences might be plausible for limited purposes such as the defence of missile silos or to complicate of enemy attack plans.

Although many of OTA's conclusions are framed in cautious language, there is no doubt that it will be hailed by opponents of SDI as a vindication of their position. More recent pronouncements by President Reagan on SDI have emphasized its usefulness as a means of persuading the Soviet Union to negotiate seriously over reducing nuclear arms: OTA says, however, that it is "unable to find anyone who could propose a plausible agreement for offensive arms reductions and a coop-

erative transition that could be reached before both the Soviets and the United States learn more about the likely effectiveness and costs of advanced ballistic missile defences... such a transition could hardly be planned until engineering development was well advanced on the actual defensive systems to be deployed. Even then, verification would be difficult".

The essence of the problem, according to OTA, is whether a vigorous US research programme, with the prospect that both sides might eventually deploy a defensive system, would make the Soviet Union more willing to negotiate deep reductions in offensive weapons. If no agreement could be reached deployment could trigger a further build up of weapons. Commenting on the OTA study this week, chairman Les Aspin of the House of Representatives Armed Services Committee said that "even if both the United States and the Soviet Union have a strategic defence system, the world could end up less safe than now". Aspin pointed out that although SDI might allow a proportion of US strategic defences to survive a Soviet first strike, its usefulness would be open to question if the Soviet Union also had a defensive system.

OTA has also just published an assessment of anti-satellite weapons (Antisatellite Weapons, Countermeasures, and Arms Control). It concludes that while arms control might reduce the threat from Soviet anti-satellite weapons, decisions to deploy such weapons should wait until the administration decides whether to go ahead with an anti-missile system, since any plausible anti-missile system would also have excellent anti-satellite potential.

Tim Beardsley

\title{
Aspects of the Mexican earthquake
}

Time: 13:17:45.4 UTC; hypocentre: $18.1^{\circ} \mathrm{N}, 102.3^{\circ} \mathrm{W} ;\left(M_{\mathrm{s}}\right): 7.8$. These are the hard facts from the US Geological Survey about the earthquake that devastated Mexico City on 19 September. The main earthquake was followed the next day by an aftershock with $M_{5}=7.3$, with a hypocentre at $18.0^{\circ} \mathrm{N}, 101.5^{\circ} \mathrm{W}$. This is towards the upper end of severity of expected aftershocks, according to the British Geological Survey (BGS). A further minor aftershock occurred on 23 September at 0945 UTC with $M_{\mathrm{s}}=4.0$, and there will be thousands of tremors below detection limits.

The hypocentres of both major shocks lie tens of kilometres landward of the trench where the Cocos plate (essentially a breakaway piece of the Pacific) is being subducted under the North American continental plate. They are both reported as "depth normal", that is, the epicentre is nominally at $33-\mathrm{km}$ depth, though the concept of a centre is not very meaningful for such large earthquakes. Records at the @) 1985 Nature Publishing Group
International Seismological Centre at Newbury, UK, show a lot of energy at long periods, which implies that the seismic moment was high. The moment is a more direct measure of the total energy involved in an earthquake than is the magnitude, as it takes into account not only the displacement, but also the rigidity and the fault area. For this earthquake, the fault is likely to be quite large and may have broken the surface, says BGS.

The disproportionate destruction of Mexico City happened because the city stands on a thick pile of unconsolidated Quaternary lake sediments and volcanic ashes deposited in an intermontane basin. The region is effectively a continuation of the Basin and Range tectonic province of California, whereas the coastal area is composed of older, harder rock. The soft lake sediments have a lower acoustic impedance than the underlying rocks, the effect of which is to increase the amplitude of the displacements for the same amount of energy.

Peter Gambles 